\title{
Stress behaviour across human tooth by temperature gradient resulting of laser irradiation
}

\author{
S. Falahatkar ${ }^{1}$, A. Nouri-Borujerdi2² ${ }^{2}$ M. Najafi ${ }^{1}$ \\ ${ }^{1}$ Department of Mechanical Engineering, Science and Research Branch, Islamic Azad University, Daneshgah Blvd, \\ Simon Bulivar Blvd, Tehran, Iran. Phone: +989111372847; Fax: +981333527614 \\ ${ }^{2}$ School of Mechanical Engineering, Sharif University of Technology, Azadi Ave, Tehran, Iran.
}

\begin{abstract}
The authors report the simulation of temperature distribution and thermally induced stress in the premolar tooth under ND-YAG pulsed laser beam. The Three-Phase-Lag (TPL) nonFourier model is proposed to describe the heat conduction in the human tooth with nonhomogeneous inner structures. A premolar tooth comprising enamel, dentin, and pulp with real shapes and thicknesses are considered and a numerical method of finite difference was adopted to solve the time-dependent TPL bio-heat transfer, strain and stress equations. The surface heating scheme is applied for simulation of laser therapy. The aim of this laser therapy is that the temperature of pulp reaches to $47^{\circ} \mathrm{C}$. The results are achieved as a function of laser heat flux showed when laser beam is irradiated downward (from the top of the tooth), the temperature and thermally induced stress increase as a function of time. The temperature increment is high on the top layers of tooth that is a result of strong absorption of beams by enamel. The thermal stress and strain in the enamel and dentin layers are more than the pulp layer that is a result of weak thermal expansion of them proportional to the pulp layer.
\end{abstract}

ARTICLE HISTORY

Revised: $8^{\text {th }}$ Sept 2019

Accepted: $8^{\text {th }}$ Sept 2019

\section{KEYWORDS}

Bio-heat equation; laser therapy;

three-phase-lag;

periodic heat flux;

numerical method.

\section{INTRODUCTION}

Application of lasers in medicine is a vast and rapidly expanding field. Laser is a very versatile tool in the techniques available of the dentist. Lasers can be used to achieve a near instant very high percentage of polymerization of resinbased materials [1]. They can also be used to activate bleaching agents for in office bleaching of stained teeth [2]. In laser dentistry, modelling and experimentation of the tooth temperature and thermally induced stresses matter because it provides us with a good insight to the laser parameters appropriate for surgery [3]. So, one can adjust them to reach better results. In this regard, Celik et al. [4] studied the thermal effects in the teeth based on the variation of thermal stress and temperature distribution. A transient thermal finite element analysis was performed to investigate the temperature distribution and the resulting thermal stress after simulated temperature changes from $36^{\circ} \mathrm{C}$ to 4 or $60^{\circ} \mathrm{C}$ for a 2 second time period. In this research, the restoration models had similar temperature distributions at 2 seconds in both the thermal conditions. Compared with $60^{\circ} \mathrm{C}$ exposure, the $4^{\circ} \mathrm{C}$ condition resulted in thermal stress values of higher magnitudes. At $60^{\circ} \mathrm{C}$, the highest stress value observed was compressive stress (42 to $43 \mathrm{MPa}$ ). Oskui et al. [5] performed a numerical study for evaluation of mechanical behaviour of human tooth. Three-dimensional finite element analysis was done on a premolar model subjected to hot and cold thermal loadings. Elapsed times for heat diffusion and stress detection at the pulp-dentin junction were calculated as measures of the pain sensation. Extreme tensile stress within the enamel resulted in damage in cold loadings. Also, extreme values of stress at the pulpal wall occurred 21.6 seconds earlier than extreme temperatures in hot and cold loadings. Denise et al. [6] demonstrated that the enamel temperature rises $77^{\circ} \mathrm{C}$ when the tooth is irradiated by laser intensity of $3 \mathrm{~W} / \mathrm{cm}^{2}$. In this investigation, the amount of temperature under laser irradiation could be higher than that detected by infrared camera. Zhou et al. [7] performed a parametric study under conditions of various laser exposure times and tissue optical properties. Goodis et al. [8] studied pulpal safety of tooth irradiated by $9.6 \mu \mathrm{m}$ laser with a repetition rate of $10 \mathrm{~Hz}$ of microsecond pulses and reported this pulsed laser beam as a reliable and safe tool for caries prevention in human tooth. Lopez et al. [9] compared the Coefficient of Thermal Expansion (CTE) with the thermo-mechanical behavior of human teeth and determined if the CTE is a suitable parameter to describe tooth behavior. The thermal strain was measured between 20 and $50^{\circ} \mathrm{C}$. Fresh dentin (human $-0.49 \% \pm 0.27$ ) contracted on heating under dry condition. Sagi et al. [10] considering a homogeneous cube for the tooth and calculated the temperature distribution of the tooth under laser beams. Malmstrom et al. [11] inspected experimentally the effects of repetition rate of $\mathrm{CO}^{2}$ laser pulses on the temperature of pulp chamber. In most of the theoretical models, the cubic geometries and homogenous constitutions were considered for tooth. Also the temperature distributions in the tooth layers were studied based on the classical Fourier's law that implies an infinite thermal propagation speed. Furthermore, a comprehensive model for temperature profile and thermal stress is missing in the literature.

In this study, the numerical solutions are carried out based on the $2 \mathrm{D}$ axisymmetric assumption for living tooth under a laser surface heating. The present work has developed a new non-Fourier bio-heat conduction model under a transient 
pulse laser irradiation. This model is based on the Three-Phase-Lag (TPL) times due to non-homogenous structure of tooth. The temperature solution resulting of TPL equation is used to predict the thermally induced stress and thermal strain in the tooth. To be precise, all tooth parts with oblique boundaries are considered. The coordinate mapping method is used for overcome to irregular geometry problem of tooth and mesh generation.

\section{PHYSICAL MODEL AND BIO-HEAT CONDUCTION}

The premolar tooth consists of two main sections such as crown and root canal. The premolar tooth has a single root canal with uneven boundaries. A 2-D model of the premolar tooth with a maximum height of $\mathrm{Z}=12 \mathrm{~mm}$, maximum radius of $\mathrm{R}=5 \mathrm{~mm}$, and initial temperature of $\mathrm{T}_{0}=37^{\circ} \mathrm{C}$ was considered (Figure 1). A dentistry laser is applied normally to the upper surface of the enamel layer with laser spot radius $r_{L} \leq 3 \mathrm{~mm}$. This laser has been selected based on the technical specification of Epic Pro team [12]. This suggestion dentistry instrument is a laser with output wavelength in range of $0.1-100 \mu \mathrm{m}$ (frequency $1 \mathrm{PHz}-10 \mathrm{THz}$ ) while the initial intensity of laser is $10 \mathrm{~W} / \mathrm{cm}^{2}$. This dentistry laser is used for premolar tooth surgery. In total 40 pulses are used for duration of $15 \mathrm{~s}$, while the intensity of laser increases from 10 to $14 \mathrm{~W} / \mathrm{cm}^{2}$. The each pulse duration (tp) of laser is 200 milliseconds. The periodical irradiation of laser on the top surface of tooth is defined with Heaviside function $(\mathrm{H})$ as:

$$
q_{L}^{\prime \prime}(t)=q_{0} H\left(t_{p}-t\right)+q_{0} \sum_{N_{p}=1}^{40}\left(1+\frac{N_{p}}{100}\right)\left\{H\left(t-0.4 N_{p}\right)-H\left(t-0.4 N_{p}-t_{p}\right)\right\}
$$

where $\mathrm{q}_{0}$ is the initial intensity of laser and $\mathrm{N}_{\mathrm{p}}$ is the pulse number. In which Heaviside function is defined as below:

$$
H(t)= \begin{cases}0 & t<0 \\ 0.5 & t=0 \\ 1 & t>0\end{cases}
$$

The heat transfer coefficient between tooth and saliva is $h=500 \mathrm{~W} / \mathrm{m}^{2} \mathrm{C}$ while the saliva temperature is $\mathrm{T}_{\mathrm{amb}}=40^{\circ} \mathrm{C}$. The bio-heat methods such as Pennes equation and thermal wave model lead to physical distortion like infinite propagation speed and temperature overshoot [7,13]. In the other hand, mismatch of material properties and variation of thermal properties are neglected by DPL Bio-heat transfer model [14], while these values might be vary from place to place in a tissue [13]. Based on a novel approach in this investigation, the properties of the tooth are considered as function of position. The TPL bio-heat equation is a new Non-Fourier method that is in conformity with this assumption. The temperature gradient is a constitutive variable in the DPL heat conduction equation, while the temperature displacement gradient is considered as a fundamental variable in the TPL heat equation [15]. The general form of the TPL non-Fourier heat equation has been presented by [15-17]. There are new parameters in the TPL non-Fourier equation such as $\mathrm{k}^{*}, \mathrm{v}$ and $\tau_{v}$ that they are the rate of thermal conductivity, thermal displacement which satisfies $\mathrm{dv} / \mathrm{dt}=\mathrm{T}$ and phase-lag of thermal displacement gradient, respectively [16]. After take the divergence of general form of TPL equation and replace the bio-heat energy balance equation inside it, the TPL bio-heat transfer is obtained. By eliminating $\mathrm{v}$ with using the first order time derivation of the TPL bio-heat equation and replace $\mathrm{dv} / \mathrm{dt}=\mathrm{T}$, the new heat conduction equation can be obtained that it is based on the non-Fourier TPL model for nonhomogeneous tooth.

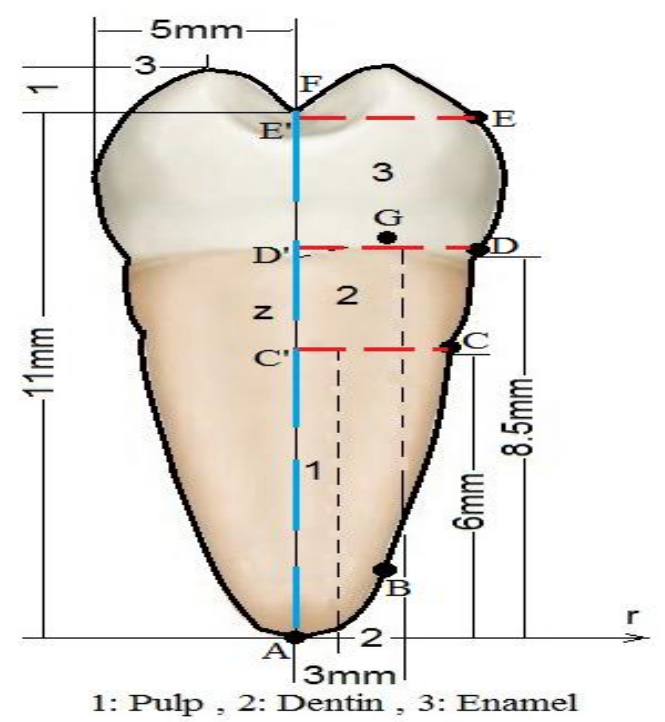

Figure 1. Premolar tooth domain considered. 


$$
\begin{aligned}
\tau_{q} \frac{\partial^{3} T_{m}}{\partial t^{3}}+\left(1+\lambda \tau_{q} \frac{W_{b} \rho_{b} C_{b}}{\rho_{m} C_{m}}\right) \frac{\partial^{2} T_{m}}{\partial t^{2}}+\left(\lambda \frac{W_{b} \rho_{b} C_{b}}{\rho_{m} C_{m}}\right) \frac{\partial T_{m}}{\partial t}= \\
\\
{\left[\beta_{m}+\left(\alpha_{m}+\beta_{m} \tau_{v}\right) \frac{\partial}{\partial t}+\left(\alpha_{m} \tau_{T}\right) \frac{\partial^{2}}{\partial t^{2}}\right] \nabla^{2} T_{m} }
\end{aligned}
$$

where, index $\mathrm{m}$ and parameter $\lambda$ are selected based on the particular sub-domains of the tooth. For the tooth pulp $\mathrm{m}=1$ and $\lambda=1$ while for dentin $(\mathrm{m}=2)$ and enamel $(\mathrm{m}=3)$, parameter of $\lambda$ is zero $(\lambda=0)$. The rate of thermal diffusivity $\left(\mathrm{m}^{2} / \mathrm{s}^{2}\right)$ is defined as $\beta=\mathrm{k}^{*} / \rho \mathrm{C}$.

\section{Thermally Induced Stress and Strain}

Thermal stress is created by any change in temperature to a material. Quick heating or cooling causes localized movement of material then thermal stress is caused. Thermal stress can lead to fracture or deformation depending on the type of material. Human tooth are subjected to many changes in temperature each day. The magnitude of the stress is proportional to the mechanical behavior of tooth structure and the temperature change inside it. The enamel and dentin layers of premolar tooth are composite structure that the mechanical behavior and the thermal properties of them differ from together [18]. When a tooth is exposed under laser irradiation, the thermally induced stress and thermal strain are more important than thermal stress resulting of hot food or liquids. The enamel and dentin layers of tooth, which have low thermal expansion and low tensile strength, may crack as a result of the laser therapy. Thus, evaluation of thermally induced stress and strain is not only important during the one time loading situation, but also must be considered as a long term fatigue problem. The thermally induced stress $(\sigma)$ and thermal strain $(\varepsilon)$ are calculated using equation given by [19]:

$$
\begin{gathered}
\sigma_{z}=-\bar{E} \bar{\alpha}_{T}\left(T-T_{0}\right)+\frac{\bar{E} \bar{\alpha}_{T}}{L} \sum_{j=1}^{n}\left(T_{j}-T_{j-1}\right) \Delta z+\bar{E} \bar{\alpha}_{T} \frac{12 z_{j}}{L^{3}} \sum_{j=1}^{n}\left(T_{j}-T_{j-1}\right) z_{j} \Delta z \\
\sigma_{r}=-\bar{E} \bar{\alpha}_{T}\left(T-T_{0}\right)+\frac{\bar{E} \bar{\alpha}_{T}}{R} \sum_{i=1}^{n}\left(T_{i}-T_{i-1}\right) \Delta r+\bar{E} \bar{\alpha}_{T} \frac{12 r_{i}}{R^{3}} \sum_{i=1}^{n}\left(T_{i}-T_{i-1}\right) r_{i} \Delta r \\
\bar{E}=E /\left(1-v^{2}\right), \quad \alpha_{T}=(1-v) \alpha_{T}, \\
\varepsilon_{z}=-\frac{v \sigma_{r}}{E}+\frac{\sigma_{z}}{E} \quad \varepsilon_{r}=\frac{\sigma_{r}}{E}-\frac{v \sigma_{z}}{E}
\end{gathered}
$$

where $v, \alpha_{\mathrm{T}}, \mathrm{E}$ and $\mathrm{T}_{0}$ are the Poisson's ratio, thermal expansion coefficient, young's modulus and initial temperature respectively.

\section{Grid Generation}

The irregular geometry of premolar tooth is important for mesh generation and numerical simulation. Representing the tooth with complex boundaries is the main reason for making grids that are not rectangular. The coordinate mapping method transfers the tooth domain into a simpler domain. Also boundaries are aligned with a constant coordinate line [14]. In this method, the $\xi$ and $\eta$ coordinates are selected based on the $r$ and $z$ directions of tooth, respectively. In other words, the $r$ and $z$ directions are defined as the dependent variables $r(\xi, \eta)$ and $z(\xi, \eta)$, based on the arbitrary points of oblique boundaries $\left(\mathrm{P}_{1}\right.$ to $\left.\mathrm{P}_{4}\right)$. In this investigation, the optional points $\mathrm{P}_{1}(\mathrm{r}=0, \mathrm{z}=0)$ and $\mathrm{P}_{2}(\mathrm{r}=4, \mathrm{z}=6 \mathrm{~mm})$ were located on the uneven edges of root canal and the $\mathrm{P}_{3}(\mathrm{r}=0, \mathrm{z}=11 \mathrm{~mm})$ and $\mathrm{P}_{4}(\mathrm{r}=5, \mathrm{z}=9 \mathrm{~mm})$ were defined on the oblique surface of enamel. The $\xi$ and $\eta$ directions were made between $\left(\mathrm{P}_{1}, \mathrm{P}_{2}\right)$ and $\left(\mathrm{P}_{2}, \mathrm{P}_{4}\right)$ respectively. Then each of them was divided by nodes $1: \mathrm{N}_{\xi}$ and $1: \mathrm{N}_{\eta}$. The boundary points of premolar tooth were detected by using of mapping coordinate equations given by [14]. The interior points of tooth domain were interpolated and defined based on these equations [14]. Figure 2 shows that the mark points of A, B, C, D, E and G in the $\xi$ and $\eta$ coordinate are consistent with the real points of premolar tooth. 


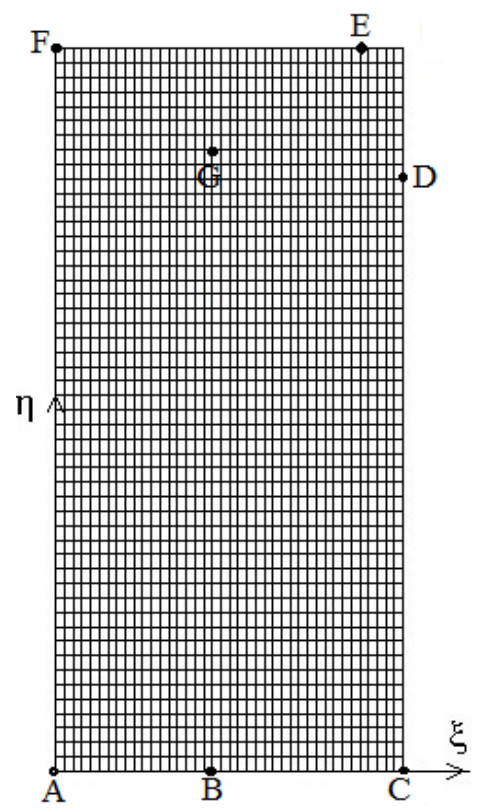
$A \mid \begin{aligned} & \xi=1 \\ & \eta=1\end{aligned}$
$\mathrm{A} \mid \begin{aligned} & \mathrm{r}(\xi, \eta)=0 \mathrm{~mm} \\ & \mathrm{z}(\xi, \eta)=0 \mathrm{~mm}\end{aligned}$
$\mathrm{B} \mid \begin{aligned} & \xi=19 \\ & \eta=1\end{aligned}$
$B \mid \begin{aligned} & r(\xi, \eta)=2.2 \mathrm{~mm} \\ & \mathrm{z}(\xi, \eta)=2.8 \mathrm{~mm}\end{aligned}$
$C \mid \begin{aligned} & \xi=41 \\ & \eta=1\end{aligned}$
$\mathrm{C} \mid \begin{aligned} & \mathrm{r}(\xi, \eta)=4 \mathrm{~mm} \\ & \mathrm{z}(\xi, \eta)=6 \mathrm{~mm}\end{aligned}$
$\mathrm{D} \mid \begin{aligned} & \xi=41 \\ & \eta=42\end{aligned}$
$\mathrm{D} \mid \begin{aligned} & \mathrm{r}(\xi, \eta)=4.8 \mathrm{~mm} \\ & \mathrm{z}(\xi, \eta)=8.5 \mathrm{~mm}\end{aligned}$
$\mathrm{E} \mid \begin{aligned} & \xi=35 \\ & \eta=51\end{aligned}$
$\mathrm{E} \mid \begin{aligned} & \mathrm{r}(\xi, \eta)=4.7 \mathrm{~mm} \\ & \mathrm{z}(\xi, \eta)=9.5 \mathrm{~mm}\end{aligned}$
$\mathrm{G} \mid \begin{aligned} & \xi=19 \\ & \eta=44\end{aligned}$
$\mathrm{G} \mid \begin{aligned} & \mathrm{r}(\xi, \eta)=2.2 \mathrm{~mm} \\ & \mathrm{z}(\xi, \eta)=8.57 \mathrm{~mm}\end{aligned}$

Figure 2. Detection of selected points in the premolar tooth.

\section{FORMULATION OF THE PROBLEM}

The governing mathematical equation (Equation. 1) becomes more complicated after using of coordinate mapping in the tooth domain, because the bio-heat equation will be discretized in the new grid system $(\xi, \eta)$ after change of variables. The new expressions are derived based on the Jacobian matrix $(\mathrm{J})$ as below:

$$
\begin{gathered}
J=\frac{\partial r}{\partial \xi} \frac{\partial z}{\partial \eta}-\frac{\partial r}{\partial \eta} \frac{\partial z}{\partial \xi} \\
\frac{\partial T}{\partial r}=\frac{1}{J}\left(\frac{\partial T}{\partial \xi} \frac{\partial z}{\partial \eta}-\frac{\partial T}{\partial \eta} \frac{\partial z}{\partial \xi}\right) \\
\frac{\partial^{2} T}{\partial r^{2}}=\frac{1}{J} \frac{\partial z}{\partial \eta} \frac{\partial}{\partial \xi}\left(\frac{1}{J}\left(\frac{\partial T}{\partial \xi} \frac{\partial z}{\partial \eta}-\frac{\partial T}{\partial \eta} \frac{\partial z}{\partial \xi}\right)\right)-\frac{1}{J} \frac{\partial z}{\partial \xi} \frac{\partial}{\partial \eta}\left(\frac{1}{J}\left(\frac{\partial T}{\partial \xi} \frac{\partial z}{\partial \eta}-\frac{\partial T}{\partial \eta} \frac{\partial z}{\partial \xi}\right)\right)
\end{gathered}
$$

The terms of $\partial \mathrm{T} / \partial \mathrm{z}, \partial^{2} \mathrm{~T} / \partial \mathrm{z}^{2}$ can be obtained similar to the above equations. By replacing these terms and Equations. (9) and (10) into the Equation. (3), the final result will be:

$$
\begin{aligned}
& \tau_{q} \frac{\partial^{3} T_{m}}{\partial t^{3}}+\left(1+\lambda \tau_{q} \frac{W_{b} \rho_{b} C_{b}}{\rho_{m} C_{m}}\right) \frac{\partial^{2} T_{m}}{\partial t^{2}}+\left(\lambda \frac{W_{b} \rho_{b} C_{b}}{\rho_{m} C_{m}}\right) \frac{\partial T_{m}}{\partial t}= \\
& {\left[\beta_{m}+\left(\alpha_{m}+\beta_{m} \tau_{v}\right) \frac{\partial}{\partial t}+\left(\alpha_{m} \tau_{T}\right) \frac{\partial^{2}}{\partial t^{2}}\right]\left[\frac{1}{J^{2}}\left(\Gamma_{1} \frac{\partial^{2} T_{m}}{\partial \xi^{2}}-2 \Gamma_{2} \frac{\partial^{2} T_{m}}{\partial \xi \partial \eta}+\Gamma_{3} \frac{\partial^{2} T_{m}}{\partial \eta^{2}}\right)+\nabla^{2} \xi \frac{\partial T_{m}}{\partial \xi}+\nabla^{2} \eta \frac{\partial T_{m}}{\partial \eta}\right]}
\end{aligned}
$$

where the main coefficients (such as $\Gamma_{1}, \Gamma_{2}$ and $\Gamma_{3}$ ) were defined as below:

$$
\Gamma_{1}=\frac{\partial r^{2}}{\partial \eta}+\frac{\partial z^{2}}{\partial \eta}, \quad \Gamma_{2}=\frac{\partial r}{\partial \xi} \frac{\partial r}{\partial \eta}+\frac{\partial z}{\partial \xi} \frac{\partial z}{\partial \eta}, \quad \Gamma_{3}=\frac{\partial r^{2}}{\partial \xi}+\frac{\partial z^{2}}{\partial \xi}
$$

\section{Initial and Boundary Conditions}

The governing equations will be solved with proper initial and boundary conditions as follow:

$$
T_{m}(\xi, \eta, 0)=37^{0} C
$$




$$
\begin{aligned}
& \frac{\partial T_{m}(\xi, \eta, 0)}{\partial t}=0 \\
& \frac{\partial^{2} T_{m}(\xi, \eta, 0)}{\partial t^{2}}=0 \\
& -k_{3} \frac{\partial T_{3}\left(\xi, N_{\eta_{3}}, t\right)}{\partial \eta}=q_{L}^{\prime \prime}+h\left[T_{a m b}-T_{3}\left(\xi, N_{\eta_{3}}, t\right)\right] \quad 0 \leq \xi \leq 5 \\
& \frac{\partial T_{m}(\xi, 1, t)}{\partial \eta}=0 \quad m=1,2,3 \quad 0 \leq \xi \leq 5 \\
& \frac{\partial T_{3}\left(N_{\xi_{3}}, \eta, t\right)}{\partial \xi}=0 \quad 0 \leq \eta \leq 8.5 \\
& k_{3} \frac{\partial T_{3}\left(N_{\xi_{3}}, \eta, t\right)}{\partial \xi}=h\left[T_{a m b}-T_{3}\left(N_{\xi_{3}}, \eta, t\right)\right] \quad 8.5 \leq \eta \leq 12 \\
& \frac{\partial T_{m}(1, \eta, t)}{\partial \xi}=0 \quad m=1,2,3 \quad 0 \leq \eta \leq 12 \\
& -k_{1} \frac{\partial T_{1}\left(N_{\xi_{1}}, \eta, t\right)}{\partial \xi}=-k_{2} \frac{\partial T_{2}\left(N_{\xi_{1}}, \eta, t\right)}{\partial \xi} \quad 0 \leq \eta \leq 6 \\
& -k_{3} \frac{\partial T_{3}\left(N_{\xi_{3}}, \eta, t\right)}{\partial \xi}=-k_{2} \frac{\partial T_{2}\left(N_{\xi_{1}}, \eta, t\right)}{\partial \xi} \quad 0 \leq \eta \leq 8.5 \\
& -k_{1} \frac{\partial T_{1}\left(\xi, N_{\eta_{1}}, t\right)}{\partial \eta}=-k_{2} \frac{\partial T_{2}\left(\xi, N_{\eta_{1}}, t\right)}{\partial \eta} \quad 0 \leq \xi \leq 1 \\
& -k_{3} \frac{\partial T_{3}\left(\xi, N_{\eta_{3}}, t\right)}{\partial \eta}=-k_{2} \frac{\partial T_{2}\left(\xi, N_{\eta_{1}}, t\right)}{\partial \eta} \quad 0 \leq \xi \leq 3
\end{aligned}
$$

\section{Method of Solution}

The uniform spatial grid of dimension $\mathrm{N}_{\xi} \times \mathrm{N}_{\eta}$ was introduced where $\Delta \xi=\mathrm{r}_{\max } /\left(\mathrm{N}_{\xi}-1\right)$ and $\Delta \eta=\mathrm{z}_{\max } /\left(\mathrm{N}_{\eta}-1\right)$ are the grid spacing and $\Delta \mathrm{t}=$ (time / number of step) denotes the time increment for each step. The Du-fort-Frankel finite difference method was applied for the numerical solution of the problem. The DFFD method is a trick which exploits the unconditional stability of the intrinsic method for heat transfer equations [20-22]. The DFFD scheme for governing equation was obtained by replacing the temperature of node $(i, j)$ at time step $(n)$ with the time average temperature of this node $T_{i, j}^{n}=\left(T_{i, j}^{n+1}+T_{i, j}^{n-1}\right) / 2$. The TPL bio-heat equation and its terms were approximated by using central difference in space and backward difference in time [21,23], while the temperature of central node (i,j) at time step (n) was eliminated based on the DFFD scheme. The forward and central differencing schemes were used for the first and second order derivatives of time, when the third order of time derivative term has been discretized by Equation. (25). The temperature distribution in the tooth layers was predicted by the calculation of $T_{i, j}$ at the time step $(n+1)$.

$$
\left(\frac{\partial^{3} T}{\partial t^{3}}\right)_{i, j}^{n}=\frac{T_{i, j}^{n+1}-3 T_{i, j}^{n}+3 T_{i, j}^{n-1}-T_{i, j}^{n-2}}{\Delta t^{3}}
$$




$$
\begin{aligned}
& T_{i, j}^{n+1}=\left(\frac{\Phi 2}{\Phi 1}\right) T_{i, j}^{n-1}+\left(\frac{\Phi 3}{\Phi 1}\right) T_{i, j}^{n-2}+\left(\frac{\Phi 4}{\Phi 1}\right) T_{i+1, j}^{n}+\left(\frac{\Phi 5}{\Phi 1}\right) T_{i-1, j}^{n}+\left(\frac{\Phi 6}{\Phi 1}\right) T_{i, j+1}^{n}+\left(\frac{\Phi 7}{\Phi 1}\right) T_{i, j-1}^{n}+ \\
& \left(\frac{\Phi 8}{\Phi 1}\right)\left(T_{i+1, j+1}^{n}-T_{i+1, j-1}^{n}-T_{i-1, j+1}^{n}+T_{i-1, j-1}^{n}\right)+\left(\frac{\Phi 9}{\Phi 1}\right) T_{i+1, j}^{n-1}+\left(\frac{\Phi 10}{\Phi 1}\right) T_{i-1, j}^{n-1}+\left(\frac{\Phi 11}{\Phi 1}\right) T_{i, j+1}^{n-1}+ \\
& \left(\frac{\Phi 12}{\Phi 1}\right) T_{i, j-1}^{n-1}+\left(\frac{\Phi 13}{\Phi 1}\right) T_{i+1, j}^{n-2}+\left(\frac{\Phi 14}{\Phi 1}\right) T_{i-1, j}^{n-2}+\left(\frac{\Phi 15}{\Phi 1}\right)\left(T_{i+1, j+1}^{n-1}-T_{i-1, j+1}^{n-1}-T_{i+1, j-1}^{n-1}+T_{i-1, j-1}^{n-1}\right)+ \\
& \left(\frac{\Phi 16}{\Phi 1}\right)\left(T_{i+1, j+1}^{n-2}-T_{i+1, j-1}^{n-2}-T_{i-1, j+1}^{n-2}+T_{i-1, j-1}^{n-2}\right)+\left(\frac{\Phi 17}{\Phi 1}\right) T_{i, j+1}^{n-2}+\left(\frac{\Phi 18}{\Phi 1}\right) T_{i, j-1}^{n-2}
\end{aligned}
$$

This algebraic equation is solved by the MATLAB programming. The discrete equation involves the constant coefficients (i.e. $\Phi 1$ to $\Phi 18$ ) that are resulted based on the discretization relations [17]. The truncation-error of this numerical solution is approximated based on the difference of partial differential equation and finite difference equation (T.E=PDE - FDE). This error order was reported as a function of terms $\left[(\Delta \mathrm{t})^{2},(\Delta \mathrm{t}),\left(\Delta \xi^{2} \Delta \eta^{2}\right),\left(\Delta \mathrm{t} \Delta \xi^{2} \Delta \eta^{2}\right),\left(\Delta \mathrm{t}^{2} \Delta \xi^{2} \Delta \eta^{2}\right)\right]$.

\section{RESULTS OF COMPUTATIONS}

The thermo-physical properties [24-26] and mechanical behavior [27-30] of the premolar tooth have been presented in Table 1. The thermal properties of blood vessel such as $\rho_{b}=1060(\mathrm{~kg} / \mathrm{m} 3)$ and $\mathrm{C}_{b}=3860(\mathrm{~J} / \mathrm{kg}$.C) were applied for numerical solution $[24,25]$. The rate of thermal conductivity was approximated as $\mathrm{k}^{*}=0.02(\mathrm{~W} / \mathrm{m}$.C.s) based on the difference of maximum and minimum values of the thermal conductivity coefficient in the whole of premolar tooth after $15 \mathrm{~s}$. The phase lag times for human tooth have been adjusted from 1 to 100 milliseconds. These parameters (i.e. $\tau_{\mathrm{q}}=16$, $\tau_{\mathrm{T}}=6$ and $\left.\tau_{v}=2 \mathrm{~ms}\right)$ are selected based on the suggestion of [16] $\left(\tau_{v} \geq k^{*} \tau_{q}, \quad k^{*} \tau_{q} \leq 2 k \tau_{T} / \tau_{q}\right)$.

The test of grid independency of the temperature solution was first performed based on the temperature distribution at the all points inside the premolar tooth. Figure 3 shows the influence of mesh density after simulation time of $20 \mathrm{~s}$, while the time step was kept at $\Delta \mathrm{t}=0.01 \mathrm{~s}$. This figure shows that by continuing increment in the mesh density from number $20 \times 25$ to $40 \times 50$, the changes of temperature at the similar points are high. But when the mesh values converted from $40 \times 50$ to $60 \times 75$, the variations in temperature profile are negligible. In other words, both the options of mesh values $(40 \times 50$ and $60 \times 75)$ have predicted the same results. It can be seen from Figure 3 that the thermal effect of laser irradiation tends to movement toward the below layers of premolar tooth. The maximum temperature of 56.4 and $55.9^{\circ} \mathrm{C}$ have been reported in the finite section of dentin layer $(\mathrm{z}=9.5 \mathrm{~mm})$ while the mesh densities were $40 \times 50$ and $60 \times 75$ respectively. After evaluation of the effect of mesh density on the numerical solution, a grid with $40 \times 50$ nodes and a time step of $0.01 \mathrm{~s}$ was selected. The lower grid density was accompanied with lower volume of calculations and lower CPU time. The grid spacing for each is equal to $\Delta \xi=0.00012 \mathrm{~m}$ and $\Delta \eta=0.00024 \mathrm{~m}$. These options are believed to be adequate so as to give satisfactory results.

Table 1. The thermo-physical properties of the tooth layers.

\begin{tabular}{lccc}
\hline Thermal properties & \multicolumn{3}{c}{ Premolar tooth layers } \\
\cline { 2 - 4 } & Pulp & Dentin & Enamel \\
\hline $\mathrm{k},[\mathrm{W} / \mathrm{m} . \mathrm{C}]$ & 0.59 & 0.65 & 0.92 \\
$\mathrm{C},[\mathrm{J} / \mathrm{kg} . \mathrm{C}]$ & 4200 & 1170 & 750 \\
$\rho,\left[\mathrm{kg} / \mathrm{m}^{3}\right]$ & 1000 & 2100 & 2900 \\
$\alpha,\left[\mathrm{m}^{2} / \mathrm{s}\right]$ & $1.4 \times 10^{-7}$ & $2.6 \times 10^{-7}$ & $4.23 \times 10^{-7}$ \\
$\mathrm{E}(\mathrm{Pa})$ & $2 \times 10^{3}$ & $1.8 \times 10^{10}$ & $8.4 \times 10^{10}$ \\
$\alpha_{T}\left(\mathrm{~K}^{-1}\right)$ & $10^{-5}$ & $10.6 \times 10^{-6}$ & $16.9 \times 10^{-6}$ \\
$v$ & 0.45 & 0.31 & 0.3 \\
$\mathrm{q}_{\mathrm{mb}},\left[\mathrm{W} / \mathrm{m}^{3}\right]$ & 1190 & 0.0 & 0.0 \\
$\mathrm{~W}_{\mathrm{b}},\left[\mathrm{m}^{3} / \mathrm{s}_{\mathrm{t}}{ }_{\mathrm{t}}\right]$ & $18 \times 10^{-4}$ & 0.0 & 0.0 \\
\hline
\end{tabular}



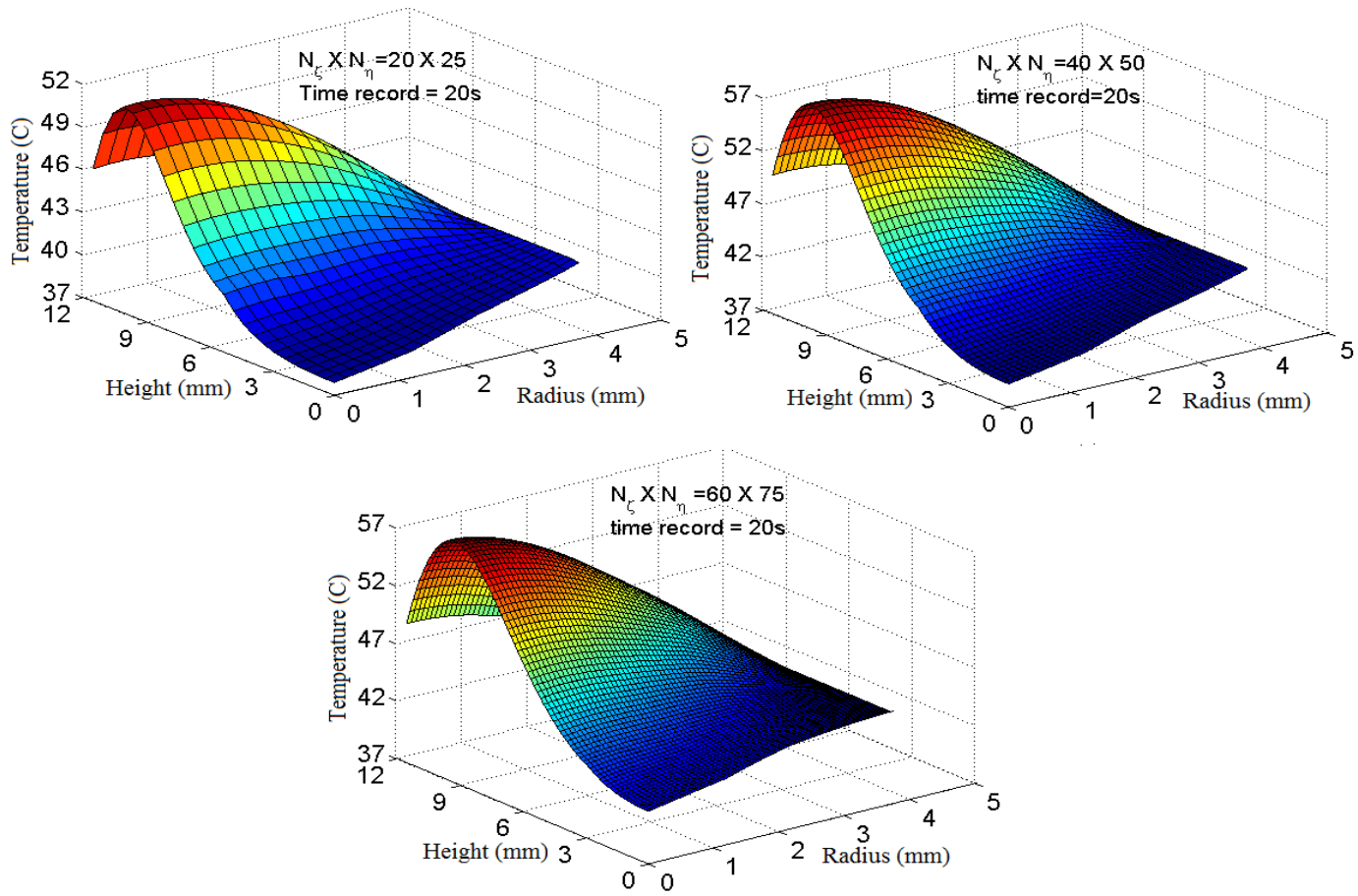

Figure 3. Grid dependency of solution at point $(\mathrm{r}=0, \mathrm{z}=0)$ with time step $(\Delta \mathrm{t}=0.01 \mathrm{~s})$.

Figure 4 shows the transient variations of dentin and pulp temperature when the suggestive dentistry laser has been applied for the tooth surgery. As can be seen in Figure 4, the dentin and pulp layers have experienced the maximum temperature 57.5 and $48.2^{\circ} \mathrm{C}$ respectively after 17 and 19 s from start of the laser treatment. This numerical solution of transient temperature has compared with the experimental observations of dentin temperature [19]. In this experimental study, the temperature increment has been made by using the electrical source on the tooth in the $5 \mathrm{~s}$ of start time. The maximum temperature of dentin has been reported as the $51.6^{\circ} \mathrm{C}$ after $6 \mathrm{~s}$ by this in vitro study. Figure 5 illustrates the time variation of thermally induced stress in the dentin based on the transient temperature of this layer at the selective point $(\mathrm{r}=0, \mathrm{z}=8.5 \mathrm{~mm})$. The numerical solution of thermal stress resulting of the laser therapy was compared with experimental results of tooth thermal therapy with electrical source [19]. This figure displays that the thermally induced stress in the dentin has increased versus of time increment. The maximum value of compressive stress is reported as 2.7 , 4.1 and $4.8 \mathrm{MPa}$ for heat fluxes of 5,10 and $15 \mathrm{~W} / \mathrm{cm}^{2}$ respectively. Also, the value of $1.2 \mathrm{MPa}$ has been observed for the thermally induced stress by heat flux of $1 \mathrm{~W} / \mathrm{cm}^{2}$ resulting of electrical source. The thermal stresses in the pulp layer have been shown to be negligible. The pulp layer is highly permeable and compliant relative to the other layers and has been modeled as a soft layer. Based on the numerical simulation of this study, maximum value of thermally induced stress in pulp is $0.3 \mathrm{~Pa}$ for heat flux of $10 \mathrm{~W} / \mathrm{cm}^{2}$.

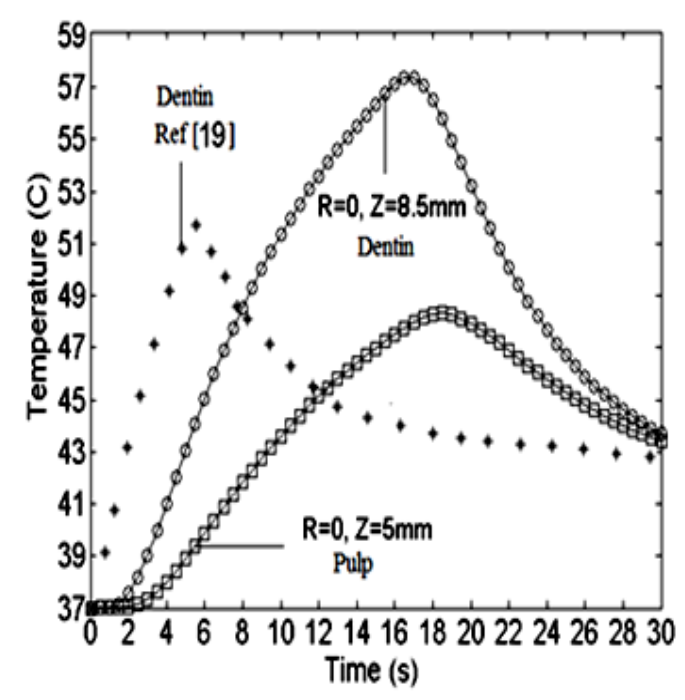

Figure 4. The transient temperature in the dentin and pulp under laser therapy.

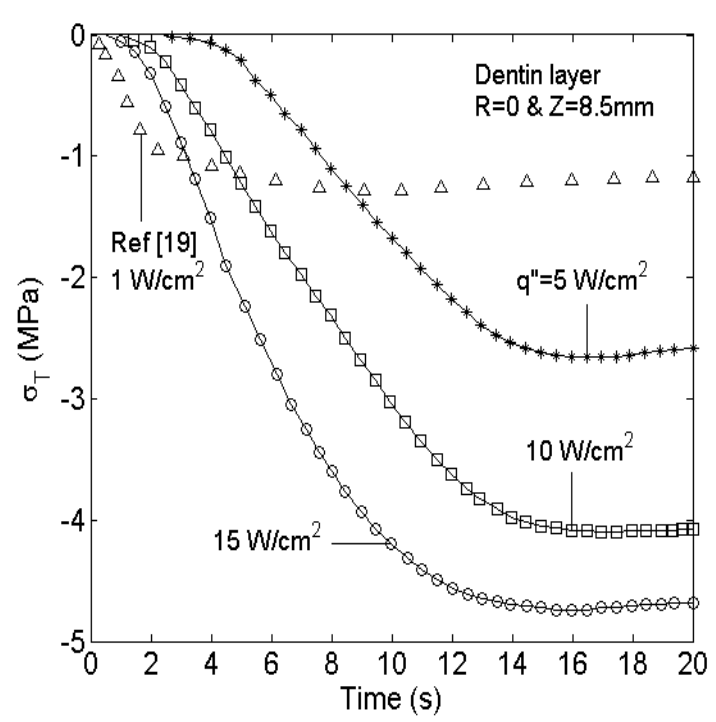

Figure 5. The transient thermal stress in the dentin under laser therapy. 
Figure 6 shows the radial temperature of premolar tooth layers, across the horizontal dashed lines that mentioned in the Figure 1. The radial distribution of temperature due to laser surface heating has been reported after $15 \mathrm{~s}$ from start of simulation. In this time, the suggestion dentistry laser has shot the final pulse of laser on the enamel surface. It can be seen from this figure that the impact of laser irradiation on the central nodes of enamel is so noticeable. The temperature values of 83,54 and $45^{\circ} \mathrm{C}$ have been obtained for center nodes of enamel, dentin and pulp respectively. The radial temperature has decreased based on the increment of radius in the constant height of enamel, dentin and pulp. The radial temperature of exterior node of tooth layers is close together. The thermo mechanical response of enamel and dentin layers can give rise to thermally induced stress in two ways. First, limitation of thermally induced strain or contraction due to the property mismatch of the interface of enamel and dentine leads to stressing and flexure even in the case of a uniform change of temperature. Second, a non-uniform distribution of temperature even in a single layer can lead to stressing through frustrated expansion/contraction. Figure 7 depicts the radial distribution of thermally induced stress in the enamel and dentin across the horizontal dashed lines in them (refer to Figure 1) after $15 \mathrm{~s}$ from start of laser therapy. It can be seen that the enamel has experienced the more thermal stress in compare with dentin. This figure shows that the thermal stress in central nodes is more than the exterior nodes. So that, the maximum values of 2.2 and $40.3 \mathrm{MPa}$ in the $\mathrm{r} / \mathrm{R}=0$ and minimum values of 0.98 and $8.2 \mathrm{MPa}$ in $\mathrm{r} / \mathrm{R}=1$ have been reported for the dentin and enamel layers respectively. The thermal strain is resulted in following of thermally induced stress distribution. Figure 8 depicts the radial variation of thermal strain across the arbitrary horizontal dashed lines in the enamel and dentin layers. This figure shows that the strain of the enamel is more than dentin layer. Based on the numerical simulation of this investigation, the values of $0.012 \%$ and $0.05 \%$ have been reported for the dentin and enamel layers respectively. It can be seen in Figure 8 that the strain curves have the downward trend versus of increment of tooth radius. Figure 9 shows the axial distribution of temperature across the vertical dashed lines in the premolar tooth layers (refer to Figure 1) when the final pulse of laser is shot (after 15s). The properties of dentistry laser and laser therapy were similar to the previous data. This figure displays that the axial distribution of temperature due to laser surface heating is critical in the top points of enamel layer. The maximum values of 103,57 and $44^{\circ} \mathrm{C}$ have been obtained for the top surface of enamel, dentin and pulp layers respectively. The temperature values of 57,44 and $41^{\circ} \mathrm{C}$ have been approximated for the lowest nodes of tooth layers respectively. In the other word, the axial temperature has increased based on the increment of height.

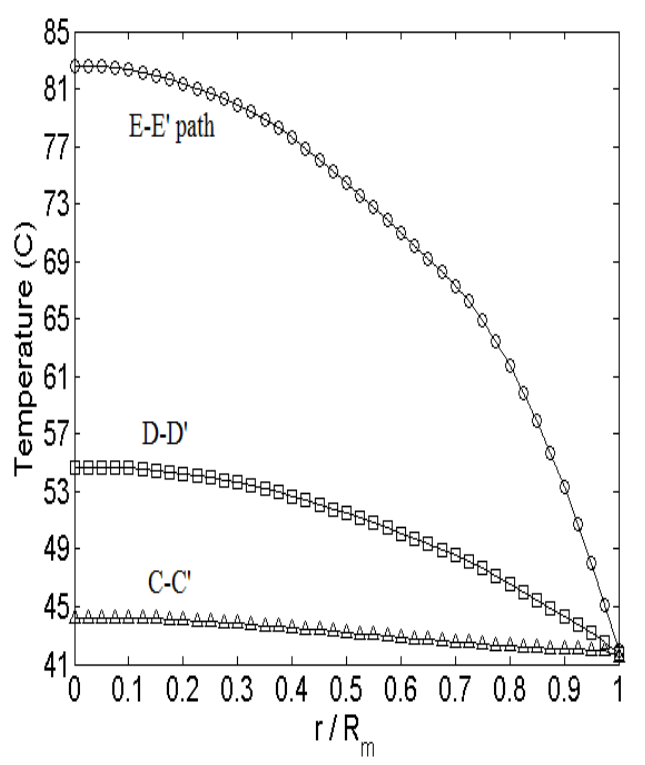

Figure 6. Temperature distribution across the horizontal paths in the tooth.
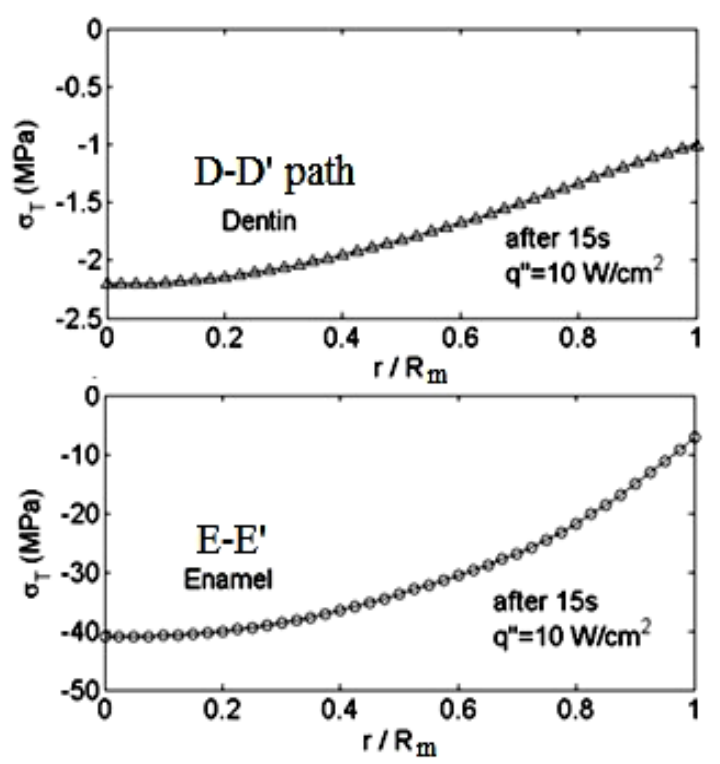

Figure 7. Thermal stress across the horizon paths in the dentin and enamel layers. 

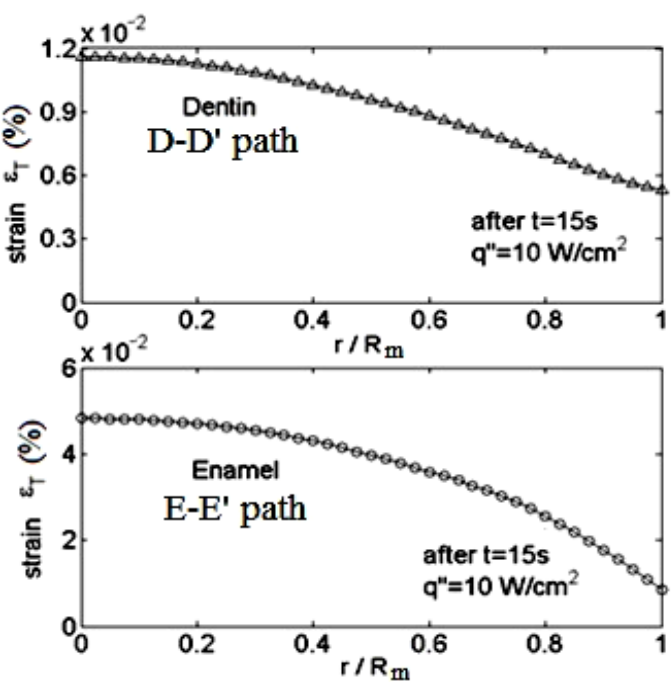

Figure 8. Thermal strain across the horizon path in the dentin and enamel.

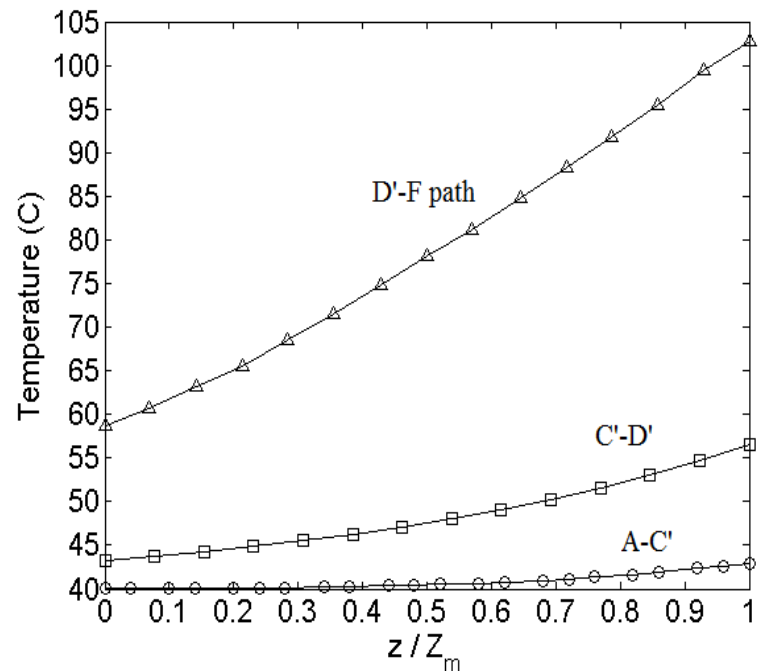

Figure 9. Temperature distribution across the vertical dashed lines in the tooth layers.

Figure 10 shows the axial distribution of stress across the vertical dashed lines in the hard solid layers of tooth (enamel and dentin) after $15 \mathrm{~s}$ from start of laser therapy. This figure displays that the enamel layer has experienced the high thermal stress in range of $18 \mathrm{MPa}$ to $109 \mathrm{MPa}$. In other word, the thermally induced stress has increased by increment of the tooth height. It can be seen that the thermally induced stress in the dentin layer is less than enamel layer. So that, the maximum value of 3.6 MPa and the minimum value of $0.9 \mathrm{MPa}$ has been reported for the top and bottom zones of the dentin layer respectively. Also, the thermal strain of the dentin and enamel layers has been presented in the next step of this study. Figure 11 shows that the strain of the enamel across the X0-X3 dashed lines is more than the dentin layer across the X3-X5 dashed lines. Based on the numerical solution of this study, the variation of thermal strain of the dentin was in range of $0.004 \%$ to $0.018 \%$, while the maximum and minimum values of $0.12 \%$ and $0.03 \%$ have been reported for the enamel. It can be seen that the strain curves tend to the increment while the height of tooth is increasing.
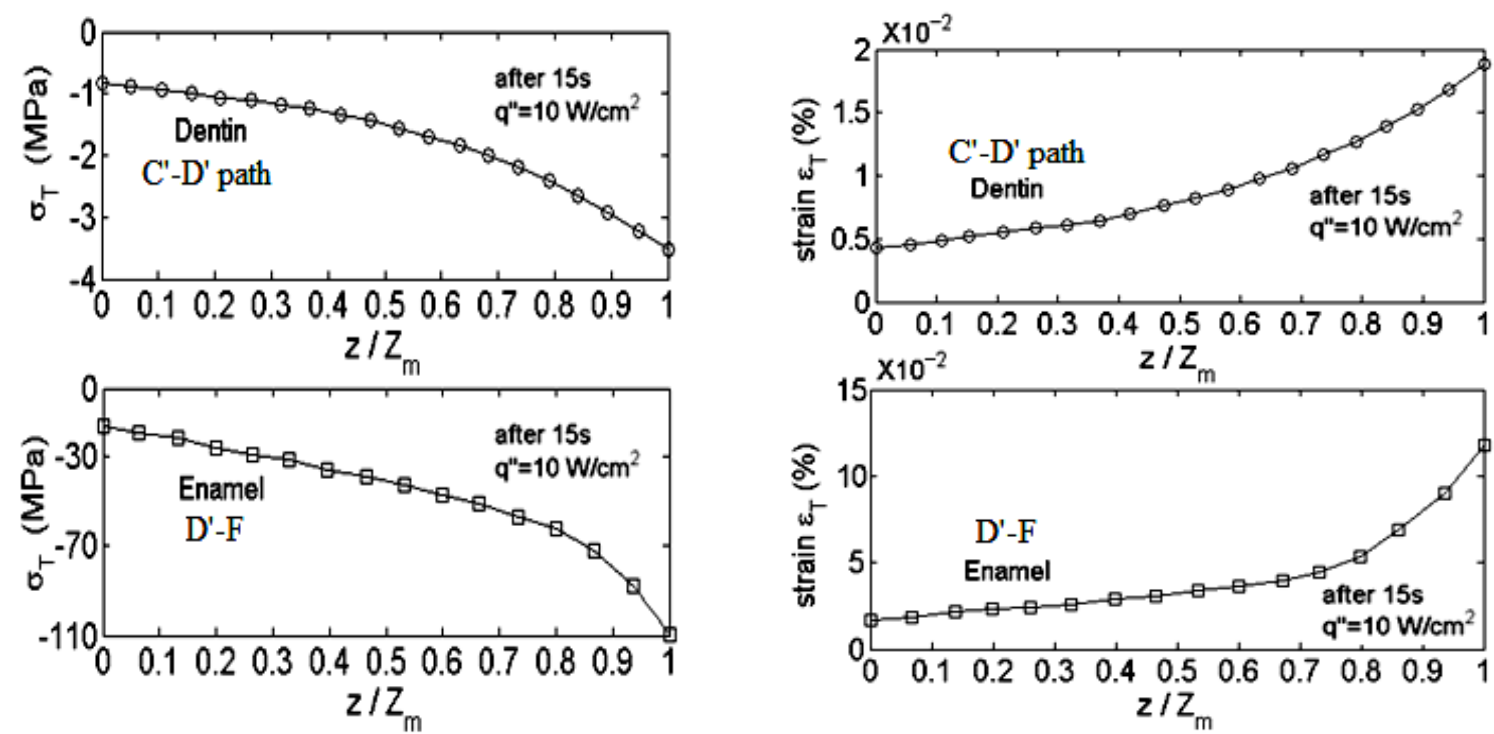

Figure 10. Thermal stress across the vertical paths in the dentin and enamel.

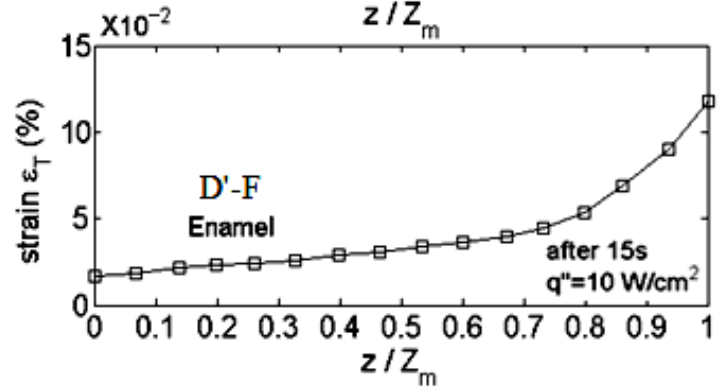

Figure 11. Thermal strain across the vertical paths in the dentin and enamel layers.

\section{CONCLUSIONS}

A numerical simulation employing the Non-Fourier bio-heat equations were used to understand how heat distribution in the premolar tooth during laser irradiation. In this investigation, new bio-heat model was used as the three phase lag time nonFourier heat conduction. The TPL bio-heat model is capable of determining the temperature distribution within the tooth layers during the tooth ablation by laser. To achieve the applicable results for biological tissues, the heat conduction equations based on the finite speed of thermal penetration were used by consider the phase lag times such as $\tau_{\mathrm{q}}, \tau_{\mathrm{T}}$ and $\tau_{v}$. The laser with surface heat flux of $10 \mathrm{~W} / \mathrm{cm}^{2}$ and pulse duration of $200 \mathrm{~ms}$ is effective for the thermal therapy of premolar tooth. Based on the numerical solution of this study, this optimum laser of dentistry has been suggested that makes adequate temperature elevation in range of 45 to $50^{\circ} \mathrm{C}$ inside the pulp layer. The laser therapy was accompanied by changes in mechanical behavior of tooth 
layers such as tension and strain. It was observed that the thermally induced stress in the enamel is more than dentin. The thermal stress values, lower than $10 \mathrm{MPa}$ has experienced in the dentin layer while this value for enamel layer is in range of 10 to $100 \mathrm{MPa}$. In other hand, the results of thermal stress in soft layer of tooth such as pulp, is very small and negligible (0.2$5 \mathrm{~Pa}$ ). Also the thermal strain in the dentin layer is lower than $0.02 \%$ but this value for enamel layer is more than $0.05 \%$. According to the reported results from this study, variations of temperature within the tooth layers satisfied the clinical protocols and are compatible with other vitro researches.

\section{REFERENCES}

[1] Sabaeian M, Shahzadeh M. Simulation of temperature and thermally induced stress of human tooth under CO2 pulsed laser beams using finite element method. Laser in Medical Science. 2013;30(2):645-51.

[2] Coutinho DS, Silveira L, Nicolau RA, Zanin F, Brugnera A. Comparison of temperature increase in vitro human tooth pulp by different light sources in the dental whitening process. Lasers in Medical Science. 2009; 24:179-185.

[3] González-Rodríguez A, López-González JD, Castillo JDL, Villalba-Moreno J. Comparison of the effects of diode laser and CO2 laser on human teeth and their usefulness in topical fluoridation. Lasers in Medical Science. 2011; 26:317-324.

[4] Çelik Köycü B, İmirzalığlu P. Heat transfer and thermal stress analysis of a mandibular molar tooth restored by different indirect restorations using a three dimensional finite element method. Journal of Prosthodontics. 2017; 26(5); 460-473.

[5] Oskui I, Ashtiani M, Hashemi A, . Effect of thermal stresses on the mechanism of tooth pain. Journal of Endodontics. 2014;40(11);1835-1839.

[6] Denise M, Zezell, Patricia A. Ana, Thiago M. Pereira, Paulo R and Walter J. Heat generation and transfer on biological tissues due to high-intensity laser irradiation. Journal of Developments in Heat Transfer. 2011; Book Chapter, InTech.

[7] Zhou J, Zhang Y, Chen K. Non-fourier heat conduction effect on laser induced thermal damage in biological tissues. Journal of Heat Transfer. 2008; A54: 1-19.

[8] Goodis HE, Fried D, Gansky S, Rechmann P, Featherstone JDB. Pulpal safety of $9.6 \mu \mathrm{m}$ TEA CO2 laser used for caries prevention. Journal of Lasers Surgery Medicine. 2004; 35(2):104-110.

[9] Lopes M, Yan Z, Consani S, Gonini A, Aleixo A, McCabe JF. Evaluation of the coefficient of thermal strain of human and bovine dentin by thermo-mechanical analysis. Brazilian Dental Journal. 2012; 23(1) :3-7.

[10] Sagi A, Segal T, Dagan J. A numerical model for temperature distribution and thermal damage calculations in teeth exposed to a CO2 laser. Mathematical Biosciences. 1984; 71:1-17.

[11] Malmstrom HS, Mc Cormack SM, Fried D, Featherstone J. Effect of CO2 laser on pulpal temperature and surface morphology: An in vitro study. Journal of Dentistry 2001; 29(8):521-529.

[12] Specification of Epic Pro dentistry laser, @; 2016; BIOLASE, Inc

[13] Zhou J, Zhang Y, Chen J. An axisymmetric dual-phase-lag bio-heat model for laser heating of living tissues. International Journal of Thermal Sciences. 2009; 48; 1477-1485.

[14] Falahatkar S, Nouri-Borujerdi A, Najafi M, Mohammad-zadeh A. Numerical solution of non-fourier heat transfer during laser irradiation on tooth layers. Journal of Mechanical Science and Technology. 2017; 31: 6085-6092.

[15] Choudhuri S. On a thermos elastic three-phase-lag model. Journal of Thermal Stresses. 2007; 30: 3: $231-238$.

[16] Quintanilla R, Racke R. A note on stability in three-phase-lag heat conduction. International Journal of Heat and Mass Transfer. 2008; 51; 1-2; 27-29.

[17] Falahatkar S, Nouri-Borujerdi A, Najafi M, Mohammad-zadeh A. Evaluation of heat conduction in a laser irradiated tooth with the three phase lag bio-heat transfer model. Thermal Science and Engineering Progress. 2018; 7; 203-212.

[18] Brown W, Jacobs H, Thompson R. Thermal fatigue in teeth, national institute for biomedical engineering and department of mechanical engineering. University of Utah. 2016.

[19] Lin M, Genin G, Xu F, Lu T. Thermal pain in teeth: Electrophysiology governed by thermo mechanics. Applied Mechanics Reviews. 2014; 66(3), 0308011-03080114.

[20] Siedlecki J, And Ciesielski M. Simulations of thermal processes in a restored tooth. Journal of Applied Mathematics and Computational Mechanics. 2013; 12(4), 103-108.

[21] Pletcher HR, Tannehill JC, Anderson DA. Computational fluid mechanics and heat transfer, 3rd Edition, CRC Press,. 2012; ISBN: 1591690374.

[22] Liang Z, Yan Y, Cai G. A Dufort-Frankel difference scheme for two-dimensional sine-gordon equation. Discrete Dynamics in Nature and Society. 2014; Vol (2014); Article ID 784387

[23] Jasinski M, Majchrzak E, Turchan L. Numerical analysis of the interactions between laser and soft tissues using generalized dual-phase lag equation. Applied Mathematical Modelling. 2016; 40; 750-762.

[24] Lin M, Xu F, Jian T, Bo L, Bai F. A review of heat transfer in human tooth - Experimental characterization and mathematical modelling. Dental materials. 2011; 26; 501-513.

[25] Martins G, Tanji EY, Wetter NU, Nogueira RD, Eduardo CP. Intrapulpal temperature during preparation with the Er: YAG laser: An in vitro study. Photomedicine and Laser Surgery. 2005; 23; 182-186.

[26] Oumer AN, Chen JLT, Azizuddin AA. A review on thermo-physical properties of bio, non-bio and hybrid nanofluids. Journal of Mechanical Engineering and Sciences. 2019;13(4), 5875-5904. 
[27] Xu HC, Lui WY, Wang T. Measurement of thermal expansion coefficient of human teeth. Australian Dental Journal. 1989; 34(6):530-535.

[28] Aziz Shah MAS, Yunus MA, Abdul Rani MN, Saman AM, M Sani MS, Mohd Zin, MS. The effect of laser stitch welding residual stress on the dynamic behaviour of thin steel structure. Journal of Mechanical Engineering and Sciences. 2019;13(4):5780-5790.

[29] Romeed SA, Malik R, Dunne SM. Stress analysis of occlusal forces in canine teeth and their role in the development of noncarious cervical lesions. International Journal of Dentistry. 2012; Article ID 234845.

[30] Al-Jethelah MSM, Dheyab HS, Khudhayer S, Ibrahim T, Al-Sammarraie AT. Latent heat storage for hot beverages. Journal of Mechanical Engineering and Sciences. 2019;13(3):5653 - 5664. 